\title{
Distribution of microelements in human articular cartilage - initial report
}

\author{
Brudnicki J', Trybus $\mathrm{M}^{1 *}$, Rapacz-Kmita $\mathrm{A}^{2}$, Merchut N², Reczyński $W^{2}$, Niewiara E ${ }^{2}$, Stodolak-Zych $\mathrm{E}^{2}$ and Pokrowiecki $\mathrm{W}^{1}$ \\ ${ }^{1}$ Clinical Department of General Surgery, Orthopaedics and Polytrauma University Hospital of Collegium Medicum Jagiellonian University Cracow, Poland \\ ${ }^{2} \mathrm{AGH}$ University of Science and Technology, Faculty of Materials Science and Ceramics Cracow, Poland
}

\begin{abstract}
The aim of this study was evaluation of distribution microelements in human articular cartilage and to determine factors influencing it. The following elements were taken under consideration: $\mathrm{Mg}, \mathrm{Ca}, \mathrm{Zn}, \mathrm{Fe}, \mathrm{Pb}$. Their concentration was assessed in the articular cartilage harvested from the loaded an unloaded area of human femoral heads. Initial results indicate that mechanical loadings are one of the important factors influencing distribution of microelements in human articular cartilage.
\end{abstract}

\section{Introduction}

Microelements $(\mathrm{Zn}, \mathrm{Mg})$ as a component of many enzymes are important factors participating in metabolism of human tissues including articular cartilage $[1,2]$. Changes in mineral composition of tissues are observed in many physiologic and pathologic situations like calcification of intervertebral disc in the process of aging or increased calcium deposit in sclerotic blood vessels [3,4]. The aim of this study was to evaluate distribution of microelements in human articular cartilage and to determine factors influencing it. The following microelements were taken under consideration: $\mathrm{Mg}, \mathrm{Ca}, \mathrm{Zn}, \mathrm{Fe}$ and $\mathrm{Pb}$. Their concentration was evaluated in the human articular cartilage harvested from loaded and unloaded area of femoral heads.

\section{Materials and methods}

Specimens were collected from loaded and unloaded area of the femoral head from macroscopically healthy hip joints from 10 consecutive men during autopsy in Institute of Forensic Medicine of Collegium Medicum Jagiellonian University in Cracow Poland. All specimens came from victims of accidents or suicidal attempts. The average age of victims was 40,9 years $(22-77$ y.o). Specimens were placed in sterile containers in the distilled water and kept in the temperature $-4{ }^{\circ} \mathrm{C}$ ant than transported in the same temperature to the laboratory of AGH University of Science and Technology, Faculty of Materials Science and Ceramics. First specimens of cartilage were placed in sterile containers and then were lyophilized in a freeze dryer (FreeZone 6 Liter, Labconco) at $-51^{\circ} \mathrm{C}$ at a pressure of $40 \mathrm{~Pa}$ for $24 \mathrm{~h}$. Than specimens were prepared for final examination with atomic-absorption spectrophotometry (AAS) on mineralizator Mutiwave 3000 Anton Paar Switzerland. Finally, the atomic-absorption spectrophotometry of specimens was performed with AAS Spectrophotometer 3110 Perkin Elmer USA. In case were specimen's volume was big enough several AAS assays of single probe were performed.

\section{Results}

The achieved results show that distribution of microelements is not homogenous even within different areas of single specimen. In such cases the average value is presented.
Concentration of investigated elements in loaded and unloaded area of femoral head is presented in charts (Charts 1-5).

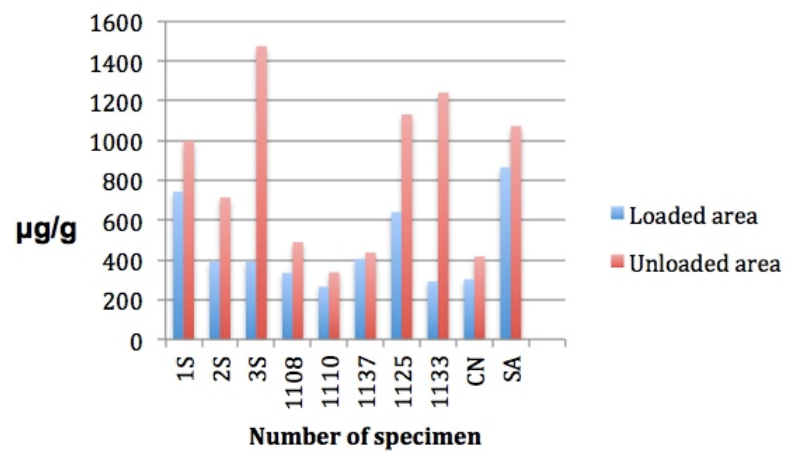

Chart 1. Concentration of $\mathrm{Mg}$ in loaded and unloaded area of femoral head

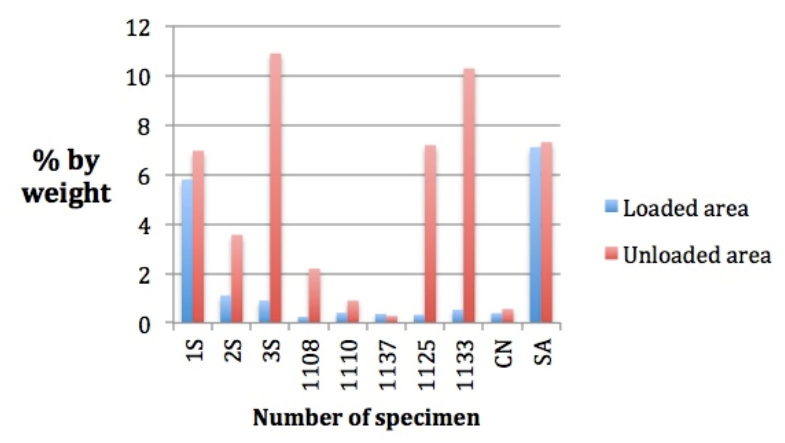

Chart 2. Concentration of $\mathrm{Ca}$ in loaded and unloaded area of femoral head

${ }^{\star}$ Correspondence to: Marek Trybus, Clinical Department of General Surgery, Orthopaedics and Polytrauma University Hospital of Collegium Medicum Jagiellonian University Cracow, Poland, E-mail: m_trybus@interia.pl

Key words: microelements, human articular cartilage, femoral head

Received: June 21, 2018; Accepted: June 30, 2018; Published: July 02, 2018 


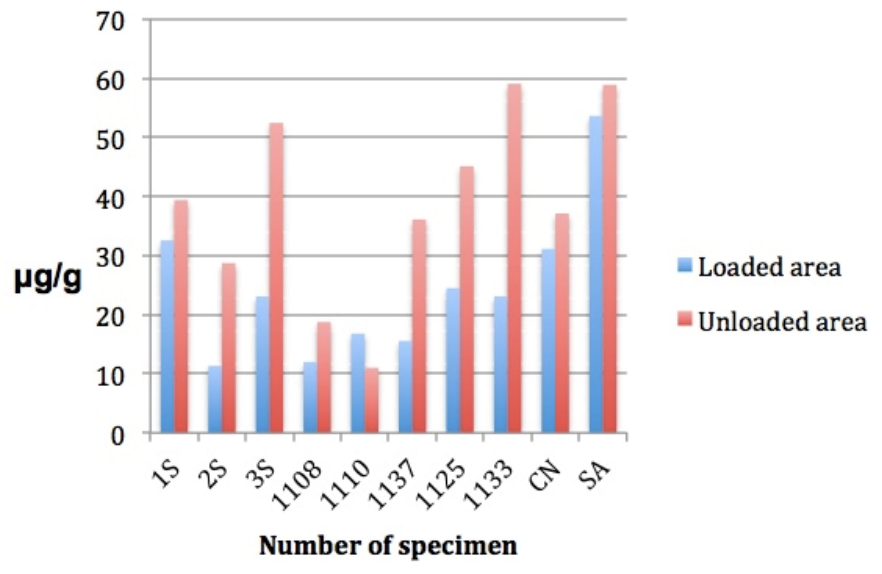

Chart 3. Concentration of $\mathrm{Zn}$ in loaded and unloaded area of femoral head

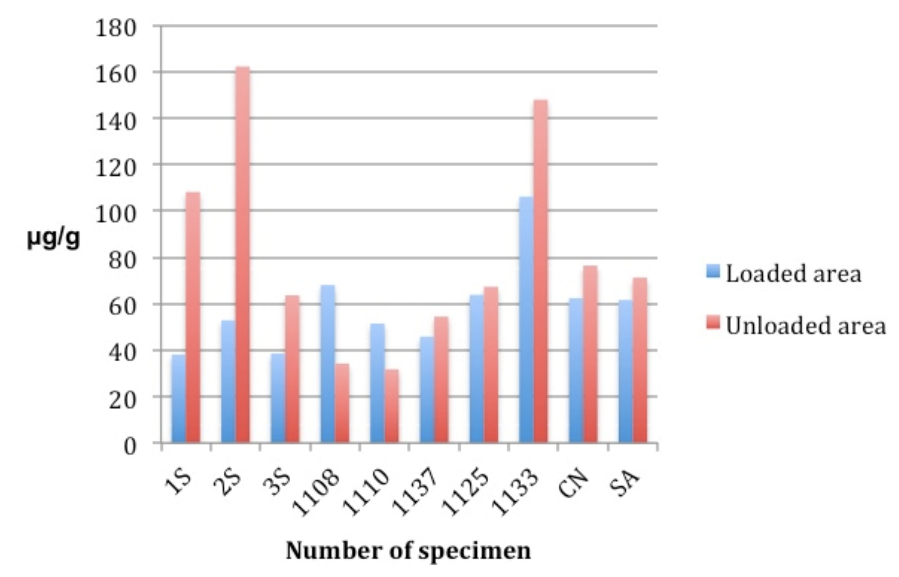

Chart 4. Concentration of Fe in loaded and unloaded area of the femoral head

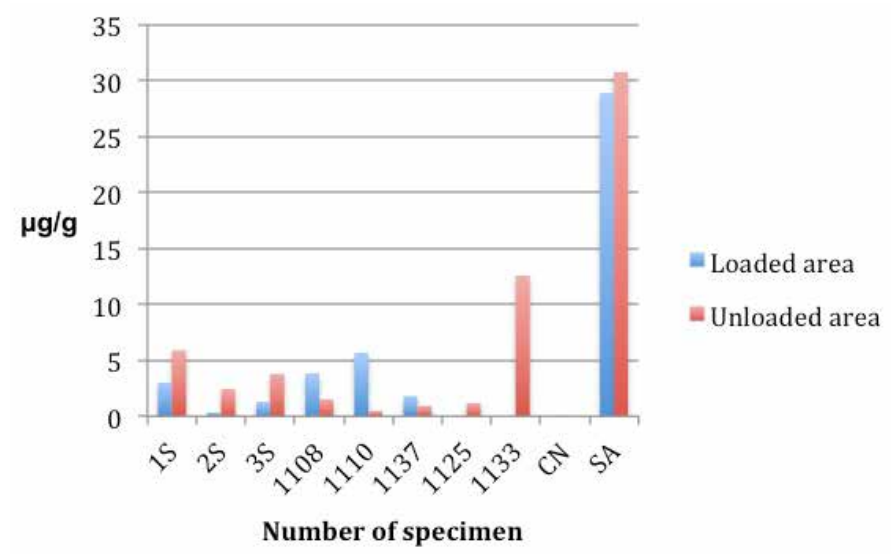

Chart 5. Concentration of $\mathrm{Pb}$ in loaded and unloaded area of femoral head

\section{Discussion}

Results achieved during investigation indicated first of all that distribution of microelements in human articular cartilage was not homogenous. It was clearly visible even during the initial phase of investigation when different concentration of elements was observed even within a single specimen. The most interesting fact was clearly visible higher concentration of investigated elements in unloaded area of the femoral head articular cartilage. This phenomenon concerns nearly all investigated elements in all specimens. Some differences were observed in case of $\mathrm{Ca}, \mathrm{Zn}, \mathrm{Fe}$ and $\mathrm{Pb}$. All this different result was noticed in three specimens. Analysis of medical history of victims from whom specimens were harvested admits of proposing a hypothetic explanation of these abnormalities. One specimen where increased level of $\mathrm{Ca}$ was observed comes from oldest victim (77y.o), which can explain increased deposit of $\mathrm{Ca}$ according to the process of aging [3,4]. Different distribution of $\mathrm{Zn}$ and $\mathrm{Fe}$ was observed in a specimen harvested from a young victim (27y.o) where advanced arteriosclerosis and fatty liver was detected during autopsy. This may indicate an important influence of general metabolic disorders on articular cartilage. Fact that in majority cases deposit of investigated elements was higher in unloaded area of femoral head articular cartilage has a great importance and requires further investigation. Different distribution of $\mathrm{Pb}$ cannot be easily explained on the base of available medical data. $\mathrm{As} \mathrm{Pb}$ is an element that in normal physiological circumstances is not present in human organism [5], its increased level can be a consequence of environmental pollutions. This thesis may be confirmed by the fact, that majority of victims came from a rural areas or small towns and the specimen where the higher concentration of $\mathrm{Pb}$ was observed comes from a victim from a great city. It is known from the literature that increased deposit of some elements in articular cartilage is observed in osteoarthritis and degeneration of joint [6]. From other site the degeneration disorders are much more often observed in weight bearing joints than in humero-scapular joint, which is a non-bearing one. Of course, the number of specimens is not big enough to conduct a statistic analysis and set up conclusions of statistic significance. This requires further investigation on a bigger number of specimens, which is planned for nearest future.

\section{Conclusion}

Distribution of microelements in human articular cartilage is a complex phenomenon depended on many factors biological, environmental and mechanical. The role of mechanical loadings on distribution of microelements in human articular cartilage may be underestimated.

\section{References}

1. Hunziker EB (2001) Articular cartilage repair: basic science and clinical progress. A review of the current status and prospects. Osteoarthritis and Cartilage 10: 432-463 [Crossref]

2. Bhosale AM, Richardson JB (2008) Articular cartilage: structure, injuries and review of management. British Medical Bulletin 87: 77-95 [Crossref].

3. Martin JA, Buckwalter JA (2002) Aging, articular cartilage chondrocyte senescence and osteoarthritis. Biogerontology 3: 257-264 [Crossref].

4. Niedzwiedzki T, Pawlikowski M, Brudnicki J, Palka E (1997) Age related mineralogical changes in the intervertebral disc and facet joints. Chir Narz Ruchu Ortop Pol 62: 39-44.

5. Zoeger N, Roschger P, Hofstaetter JG (2006) Lead accumulation in tidemark of articular cartilage. OsteoArthritis and Cartilage 14: 906-913.

6. J. Sanchez-Adams, Leddy HA, McNulty AL, O'Conor CJ, Guilak F (2014) The Mechanobiology of Articular Cartilage: Bearing the Burden of Osteoarthritis. Curr Rheumatol Rep 16: 1-15.

Copyright: $\odot 2018$ Brudnicki J. This is an open-access article distributed under the terms of the Creative Commons Attribution License, which permits unrestricted use, distribution, and reproduction in any medium, provided the original author and source are credited. 